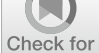

updates

Cite as

Nano-Micro Lett.

(2019) 11:60

Received: 30 April 2019

Accepted: 27 June 2019

Published online: 17 July 2019

(C) The Author(s) 2019

\section{High-Performance Na-Ion Storage of S-Doped Porous Carbon Derived from Conjugated Microporous Polymers}

Yuquan $\mathrm{Li}^{1}$, Bin $\mathrm{Ni}^{1}$, Xiaodan $\mathrm{Li}^{2}$, Xianghui Wang ${ }^{1}{ }^{凶}$, Dafeng Zhang ${ }^{3}$, Qingfei Zhao ${ }^{5}$, Jinliang $\mathrm{Li}^{2} \bowtie$, Ting $\mathrm{Lu}^{1,4}$, Wenjie $\mathrm{Mai}^{2}$, Likun Pan $^{1}$

Yuquan Li and Bin Ni have contributed equally to this work.

$\triangle$ Xianghui Wang, xhwang@phy.ecnu.edu.cn; Jinliang Li, lijinliang@email.jnu.edu.cn; Ting Lu, tlu@phy.ecnu.edu.cn

1 Shanghai Key Laboratory of Magnetic Resonance, School of Physics and Electronic Science, East China Normal University, 3663 N. Zhongshan Rd., Shanghai 200062, People's Republic of China

2 Siyuan Laboratory, Guangdong Provincial Engineering Technology Research Center of Vacuum Coating Technologies and New Energy Materials, Department of Physics, Jinan University, Guangzhou 510632, Guangdong, People's Republic of China

3 School of Materials Science and Engineering, Liaocheng University, Liaocheng 252000, Shandong, People's Republic of China

4 Department of Chemical Engineering, School of Environmental and Chemical Engineering, Shanghai University, 99 Shangda Road, Shanghai 200444, People's Republic of China

5 Testing and Analysis Centre, College of Chemistry and Materials Science, Shanghai Normal University, 100 Guilin Road, Shanghai 200234, People's Republic of China

\title{
HIGHLIGHTS
}

- S-doped porous carbons (SCs) derived from conjugated microporous polymers were synthesized for Na-ion batteries.

- The SCs exhibited a high capacity of $440 \mathrm{mAh} \mathrm{g}^{-1}$ at $50 \mathrm{~mA} \mathrm{~g}^{-1}$ and excellent cycling performance.

- Ex situ X-ray photoelectron spectroscopy was used to investigate the electrochemical reaction mechanism of the SCs.

\begin{abstract}
Na-ion batteries (NIBs) have attracted considerable attention in recent years owing to the high abundance and low cost of $\mathrm{Na}$. It is well known that $\mathrm{S}$ doping can improve the electrochemical performance of carbon materials for NIBs. However, the current methods for $\mathrm{S}$ doping in carbons normally involve toxic precursors or rigorous conditions. In this work, we report a creative and facile strategy for preparing S-doped porous carbons (SCs) via the pyrolysis of conjugated microporous polymers (CMPs). Briefly, thiophene-based CMPs served as the precursors and doping sources simultaneously. Simple direct carbonization of CMPs produced S-doped carbon materials with highly porous structures. When used as an anode for NIBs, the SCs exhibited a high reversible capacity of $440 \mathrm{mAh} \mathrm{g}^{-1}$ at $50 \mathrm{~mA} \mathrm{~g}^{-1}$ after 100 cycles, superior rate capability, and excellent cycling stability $\left(297 \mathrm{mAh} \mathrm{g}^{-1}\right.$ after 1000
\end{abstract}

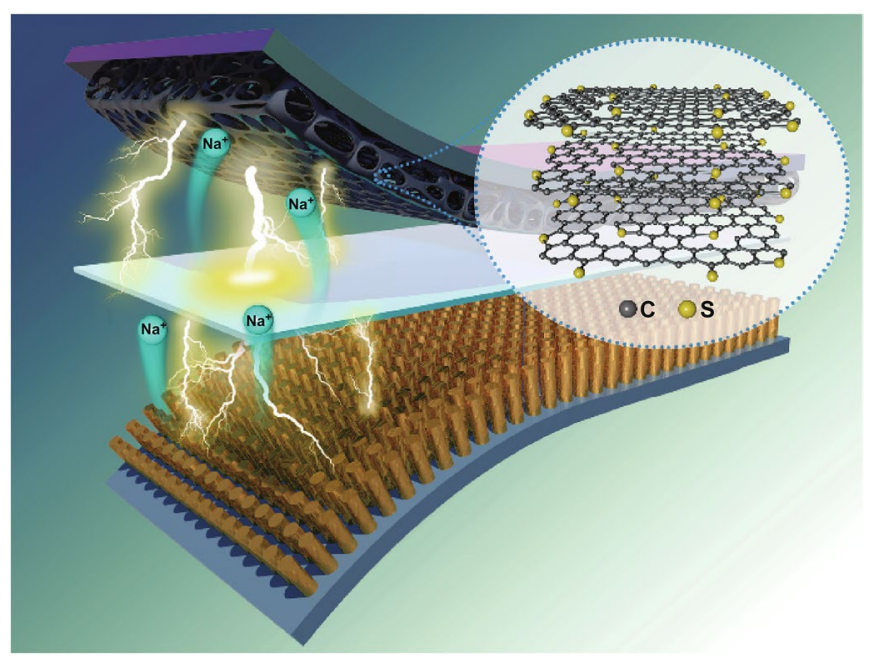


cycles at $500 \mathrm{~mA} \mathrm{~g}^{-1}$ ), outperforming most S-doped carbon materials reported thus far. The excellent performance of the SCs is attributed to the expanded lattice distance after S doping. Furthermore, we employed ex situ X-ray photoelectron spectroscopy to investigate the electrochemical reaction mechanism of the SCs during sodiation-desodiation, which can highlight the role of doped S for Na-ion storage.

KEYWORDS Conjugated microporous polymer; S-doped porous carbons; Na-ion batteries; Reaction mechanism

\section{Introduction}

Recently, Li-ion batteries (LIBs) have seen tremendous progress owing to the significant development of electrical devices and electric vehicles [1-4]. However, the emerging demand for LIBs has resulted in a latent shortage of Li. Therefore, Na-ion batteries (NIBs), as one of the potential alternatives to LIBs, have attracted increasing research attention owing to the low cost and eco-friendliness of $\mathrm{Na}$ [5-8]. However, the radius of the $\mathrm{Na}$ ion is larger than that of the $\mathrm{Li}$ ion; therefore, the diffusion of $\mathrm{Na}$ ions is hindered in the NIB system. Hence, it remains a challenge to find a suitable accommodator to realize reversible and fast insertion-extraction of $\mathrm{Na}$ ions [9-11].

Carbonaceous materials are candidates for the anode of NIBs, owing to their abundance, superior conductivity, and outstanding stability $[12,13]$. In numerous studies, carbonaceous materials have exhibited excellent cycling stability as the anode for NIBs [14-16]. However, owing to the low diffusion coefficient of $\mathrm{Na}$, carbonaceous materials deliver a poor reversible capability $[17,18]$. It is well known that introducing heteroatoms, such as $\mathrm{S}$, can modify the structure and enhance the electrical conductivity of carbon materials [17, 19-21]. Additionally, S doping has been shown to improve the Na-ion storage capability of carbon materials by producing defects and pores [22] and increasing the interlayer distance $[10,23]$. For example, by conducting pyrolysis of 1,4,5,8-naphthalenetetracarboxylic dianhydride in $\mathrm{S}$ steam, Li et al. [9] obtained S-doped disordered carbon with a high initial reversible capacity of $516 \mathrm{mAh} \mathrm{g}^{-1}$ at $20 \mathrm{~mA} \mathrm{~g}^{-1}$ for NIBs. Yang et al. [24] prepared S-doped $\mathrm{N}$-rich carbon via thermolysis of N-rich carbon in an $\mathrm{H}_{2} \mathrm{~S} /$ $\mathrm{Ar}$ atmosphere, which delivered excellent reversibility for $\mathrm{Na}$-ion storage $\left(350 \mathrm{mAh} \mathrm{g}^{-1}\right.$ at $50 \mathrm{~mA} \mathrm{~g}^{-1}$ ). Hong et al. [25] obtained S-doped hard carbon through the molten salts method using $\mathrm{S}$ and $\mathrm{Na}_{2} \mathrm{~S}_{2} \mathrm{O}_{3}$ powders as $\mathrm{S}$ sources, which exhibited a capacity of $200 \mathrm{mAh} \mathrm{g}^{-1}$ at $1000 \mathrm{~mA} \mathrm{~g}^{-1}$. These studies indicate that $\mathrm{S}$ exhibits high activity with a reversible electrochemical reaction for Na-ion storage when it is doped in carbonaceous materials. However, the methods used in previous studies for $\mathrm{S}$ doping suffer from several shortcomings, including toxic precursors, complex processes, and strict conditions. Additionally, the Na-ion storage capacity of the reported S-doped carbon must be improved for practical applications. Therefore, developing a facile approach for the preparation of high-performance S-doped carbon materials remains highly challenging [26].

As organic porous polymers, conjugated microporous polymers (CMPs), which are composed of lightweight elements and connected by inherent $\pi$ conjugation and strong covalent linkage, are attracting attention [27, 28]. CMPs have a wide range of potential applications, including gas adsorption, catalysis [29], sensors [30], and energy storage [31-34], owing to their tunable and flexible structures [35, 36]. In particular, CMPs with a suitable porosity and heteroatom doping level can be obtained by tuning their porous architectures and functional groups, respectively, which are the ideal precursors for in situ heteroatom-doped carbons [37-39]. For example, Zhuang et al. [40] obtained B, N-codoped porous carbons derived from CMPs and found that the rich $\mathrm{B}, \mathrm{N}$-doped porous carbons exhibited high catalytic performance for the oxygen reduction reaction (ORR). Hao et al. [41] prepared $\mathrm{N}$-doped carbon materials derived from CMPs with a specific capacitance of $151 \mathrm{~F} \mathrm{~g}^{-1}$ at $0.1 \mathrm{~A} \mathrm{~g}^{-1}$ for a supercapacitor. Recently, Su et al. [42] synthesized $\mathrm{N}, \mathrm{S}$-co-doped carbon nanosheets through the activation of S-doped CMPs at different temperatures in an ammonia atmosphere, which exhibited high catalytic performance for the ORR. These aforementioned works offer a facile strategy for the in situ preparation of S-doped porous carbons (SCs) from CMPs and indicate the possibility of applying the SCs to the anodes of NIBs owing to their superior structure and electrochemical behaviors. However, relevant exploration has not been performed.

In this work, a S-containing thiophene-based CMP (SCMP) was prepared through a conventional solution phase reaction method and used as the precursor as well as the doping source for in situ preparation of SCs. Owing to the 
abundance and regular distribution of S atoms in the SCMP precursor, the $\mathrm{S}$ element was successfully doped into the carbon skeletons. The as-prepared SCs exhibited excellent $\mathrm{Na}$-ion storage performance, indicating their potential for high-performance NIBs.

\section{Experimental}

\subsection{Synthesis}

In a typical procedure, $6.0 \mathrm{~g}$ of 1,2,4,5-benzenetetracarboxylic anhydride (PDA) and $20.0 \mathrm{~g}$ of phosphorus pentasulfide were dissolved in a xylene solution $(150 \mathrm{~mL})$. Then, the mixture was vigorously stirred at $120{ }^{\circ} \mathrm{C}$ for 7 days under a reflow process. After the reaction, the black powder was collected via filtration, and then the powder was further extracted using tetrahydrofuran in a Soxhlet apparatus for 3 days and dried at $80{ }^{\circ} \mathrm{C}$ for $12 \mathrm{~h}$. The obtained SCMP was carbonized at different temperatures for $4 \mathrm{~h}$ with a heating rate of $5{ }^{\circ} \mathrm{C} \min ^{-1}$ in a $\mathrm{N}_{2}$ atmosphere. Subsequently, the samples were immersed in water at $70{ }^{\circ} \mathrm{C}$ overnight, followed by washing. The obtained products were dried at $60{ }^{\circ} \mathrm{C}$ for $6 \mathrm{~h}$. To evaluate the economy of our SCs, the yield of polymerization and the quality after pyrolysis were examined. More than $3.7 \mathrm{~g}$ of SCMP was obtained after the polymerization of $6.0 \mathrm{~g}$ of PDA and purification through Soxhlet extraction. Finally, approximately $1.2 \mathrm{~g}$ of the sample was obtained after carbonization. PDA is a low-cost CMP precursor ( $\$ 60$ per $\mathrm{kg}$ ); most organic units for preparing microporous polymers are more expensive. Additionally, most S-doped carbon materials used for SIBs employ powdered $\mathrm{S}$ and $\mathrm{H}_{2} \mathrm{~S}$ as doping sources. During the pyrolysis of powdered $\mathrm{S}$ and $\mathrm{H}_{2} \mathrm{~S}$, a significantly larger amount of $\mathrm{S}$ is wasted in the tail gas compared with our pyrolysis process, which is environmentally unfriendly for large-scale production. Our approach is an economical and scalable method to obtain S-doped carbon for SIB applications.

\subsection{Materials Characterization}

To study the bond structure of SCMP, the as-prepared polymer was characterized via Fourier transform infrared (FTIR) spectroscopy and ${ }^{13} \mathrm{C}$ nuclear magnetic resonance (NMR) spectroscopy (Bruker AVANCE III
300 Spectrometer). Powder X-ray diffraction (XRD, Bruker) patterns were obtained using $\mathrm{Cu} \mathrm{K} \alpha$ radiation ( $\lambda=1.5406 \AA)$. The morphologies and structures of the samples were observed via scanning electron microscopy (SEM, S-4800, Hitachi) and transmission electron microscopy (TEM, JEM-2010, JEOL). A multifunctional X-ray photoelectron spectrometer (XPS, ESCALAB 250XI, Thermo Scientific) was employed to analyze the chemical states and compositions of the samples. Raman spectra were obtained using a Raman spectrometer (RM-1000, Renishaw) with a laser having a wavelength of $632.8 \mathrm{~nm}$. The carbon conversion rate of the SCMP was characterized via thermogravimetric analysis (TGA, TGA/DSC $1 / 1600 \mathrm{HT}$, Metter), under heating from room temperature to $1000{ }^{\circ} \mathrm{C}$ with a heating rate of $10{ }^{\circ} \mathrm{C} \mathrm{min}-1$ in a $\mathrm{N}_{2}$ atmosphere. The $\mathrm{N}_{2}$ adsorption-desorption isotherms were obtained at $77 \mathrm{~K}$ using an Autosorb iQ2 system (Quantachrome Instruments), and the specific surface area and pore-size distribution were calculated from the adsorption data using the Brunauer-Emmett-Teller (BET) model.

\subsection{Electrochemical Testing}

In a typical procedure, active materials, carbon black and carboxymethyl cellulose were mixed in water with a weight ratio of 8:1:1 for homogenous sizing. Then, the solution was coated onto $\mathrm{Cu}$ foil and dried at $120^{\circ} \mathrm{C}$ for $24 \mathrm{~h}$. The mass of the active materials for each electrode

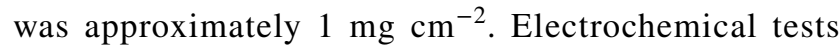
were conducted at atmospheric temperature in coin cells (C2032-type), which were assembled in an MBraun glovebox filled with Ar. In the coin cells, the counter electrode was $\mathrm{Na}$ metal foil, the separator was a glass fiber filter (Whatman), and the electrolyte was ethylene carbonate and propylene carbonate $(1: 1, \mathrm{w} / \mathrm{w})$ with $1 \mathrm{M} \mathrm{NaClO}_{4}$. The cycling performance and galvanostatic charge/discharge curves of the electrodes were evaluated using a LAND 2001A battery test system in the voltage range of 0.005-3.0 V. Unless otherwise noted, cyclic voltammetry (CV) was performed using an Autolab electrochemical workstation (PGSTAT 204) at a sweep rate of $0.2 \mathrm{mV} \mathrm{s}^{-1}$. Electrochemical impedance spectroscopy (EIS) was performed using the same electrochemical workstation after 100 cycles in the frequency range of $0.1 \mathrm{~Hz}$ to $100 \mathrm{kHz}$. 


\section{Results and Discussion}

\subsection{Structural Characterizations}

The typical fabrication method for the SCMP is illustrated in Fig. S1. The SCMP was polymerized by a PDA monomer with phosphorus pentasulfide in xylene for 7 days. During the process, phosphorus pentasulfide, which is a commonly used thionating reagent, caused the PDA to undergo a sequence of thionation, isomerization, and polymerization reactions [42]. To prove that the SCMP was polymerized, the solid-state ${ }^{13} \mathrm{C}$ NMR spectra of the SCMP were obtained, as shown in Fig. S2. ${ }^{13} \mathrm{C}$ peaks for the SCMP at 138.5, 129.7, and $123.7 \mathrm{ppm}$ were detected, which are attributed to the $\mathrm{C}-\mathrm{S}, \mathrm{C}_{\mathrm{C}-\mathrm{S}}-\mathrm{C}-\mathrm{C}_{\mathrm{C}-\mathrm{H}}$, and $\mathrm{C}-\mathrm{H}$ bonds, respectively, indicating that the polymerization occurred as expected. Additionally, there was a peak near $175 \mathrm{ppm}$, which is attributed to the unreacted anhydride $\mathrm{C}\left(\mathrm{C}_{\mathrm{C}=\mathrm{O}}\right)$ from the PDA monomer. The FTIR spectra were also obtained, to confirm the polymerization. In Fig. S3, the FTIR absorption bands at 1771 and $1858 \mathrm{~cm}^{-1}$ are attributed to $\mathrm{C}=\mathrm{O}$ vibration in the
PDA monomer. After the polymerization, these absorption bands disappeared, and new absorption bands at 1612 and $1438 \mathrm{~cm}^{-1}$ emerged, which are assigned to the newly formed $\mathrm{C}=\mathrm{C}$ bond [42]. To measure the carbon content, the TGA curve of the SCMP in $\mathrm{N}_{2}$ was obtained, as shown in Fig. S4. Considering the relatively low thermostability of the thiophene and sulfonate group compared with the carbon skeleton, the large weight loss during carbonization is ascribed to the decomposition of these functional groups. Finally, the SCs were obtained via the pyrolysis of the SCMP at different temperatures in $\mathrm{N}_{2}$. Samples carbonized at $600,700,800$, and $900{ }^{\circ} \mathrm{C}$ are denoted as SC-600, SC-700, SC-800, and SC-900, respectively.

Figure 1a-d shows SEM images of SC-600, SC-700, SC-800, and SC-900. All the SCs exhibited similar structures, indicating the stability of the SCMP-converted carbon matrix. To analyze the distribution of $\mathrm{S}$ in the SCs, energy-dispersive X-ray spectroscopy (EDS) elemental mapping was performed, as shown in Fig. 1e. We clearly observed that $\mathrm{S}$ was homogeneously distributed in SC-800, indicating that $\mathrm{S}$ was doped in the SCs. Figure $1 \mathrm{f}$ presents
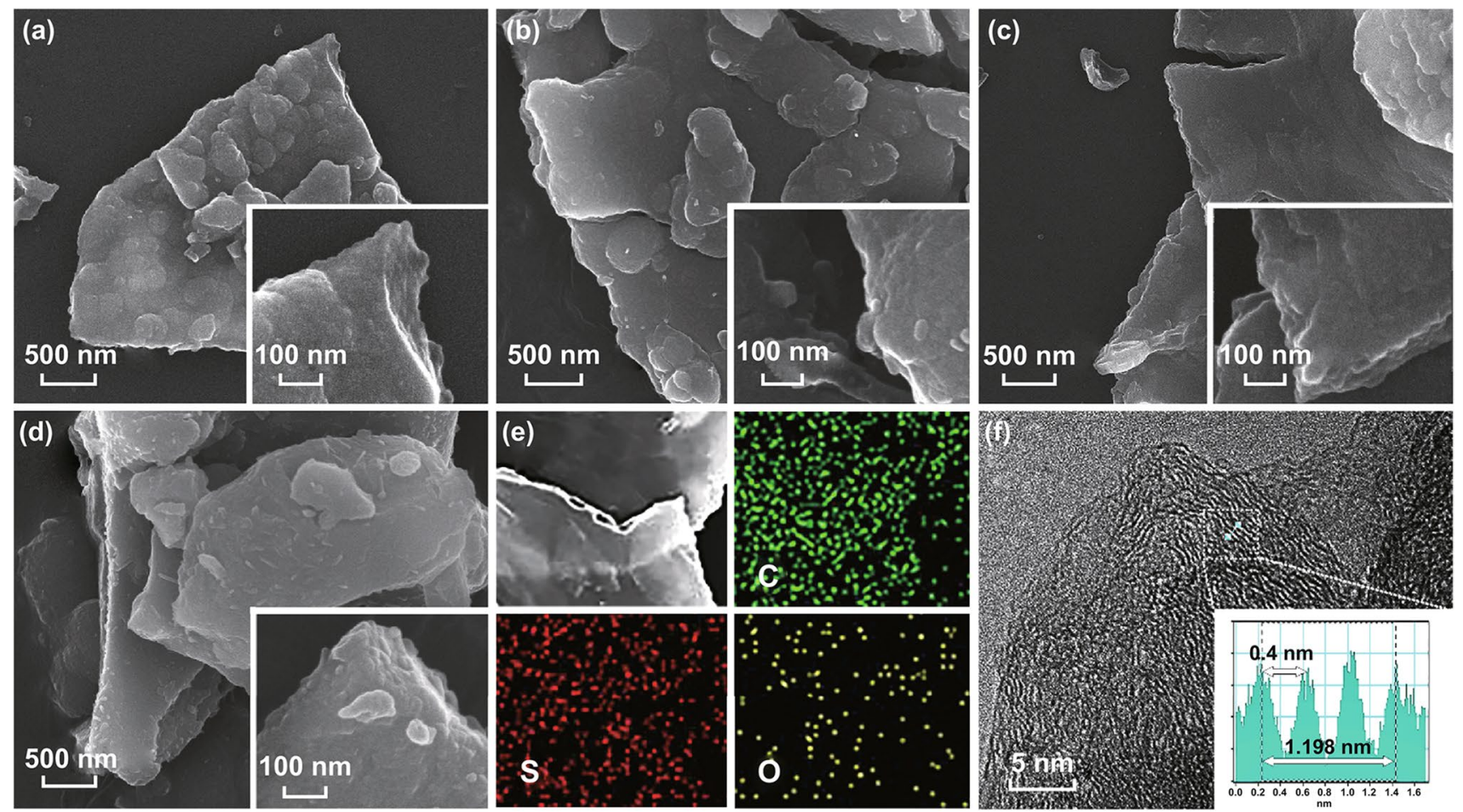

Fig. 1 SEM images of a SC-600, b SC-700, c SC-800, and d SC-900. The insets show the corresponding magnified SEM images. e EDS elemental mapping of SC-800. f HRTEM image of SC-800. The inset shows the average interlayer distance at the electronic scale 
a high-resolution TEM (HRTEM) image of SC-800. As shown, a disorder interlayer distance was detected. After the disposition of the micro-region (inset in Fig. 1f), the average interlayer distance was $0.40 \mathrm{~nm}$, which is larger than that for graphite. HRTEM images of SCs carbonized at other temperatures are displayed in Fig. S5, which all exhibited an expanded average interlayer distance of approximately $0.4 \mathrm{~nm}$. The expanded interlayer distance of the SCs was expected to facilitate the insertion of $\mathrm{Na}$ ions into the layers [43].

Owing to the larger covalent diameter of S compared with $\mathrm{C}$, the substitution of $\mathrm{C}$ by $\mathrm{S}$ in the carbonaceous material
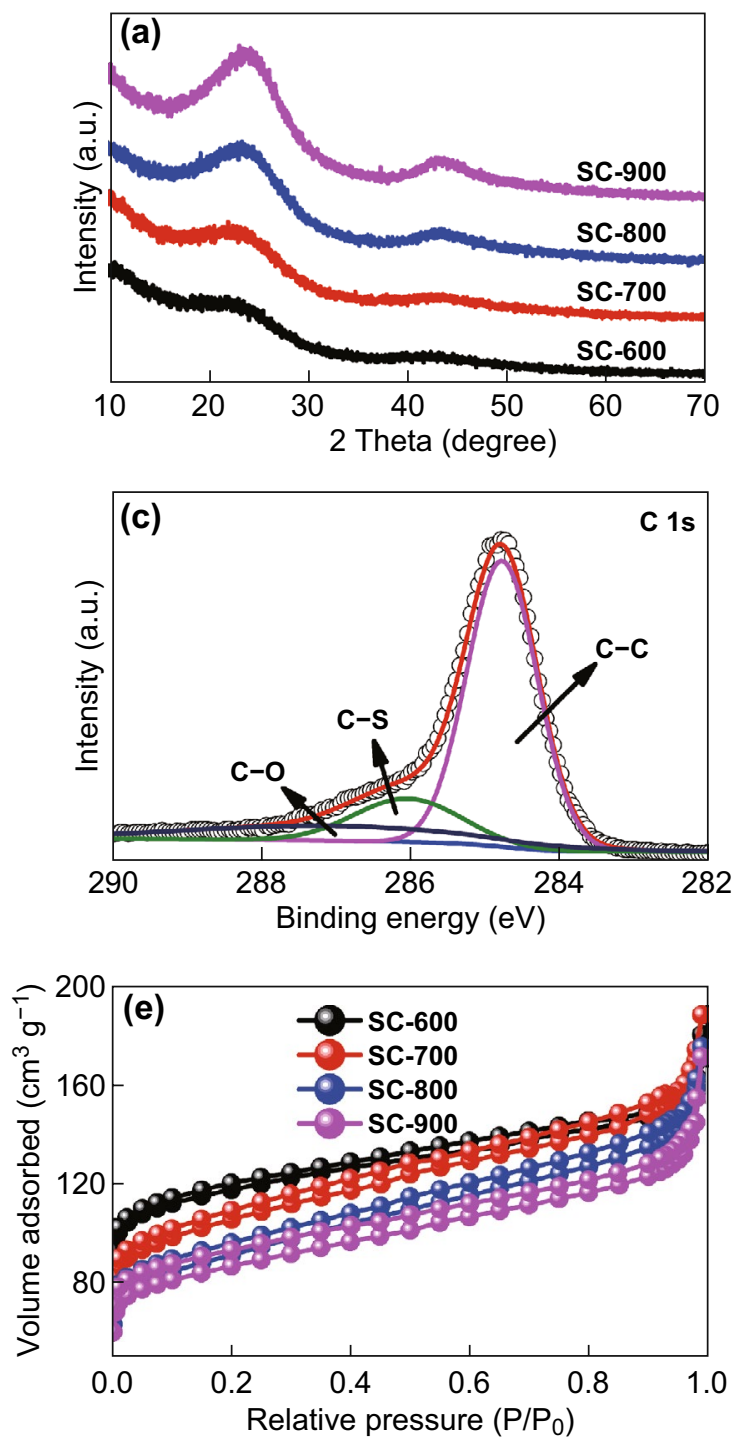

increased the spacing between adjacent sheets, as indicated by HRTEM $[9,44]$. To confirm this, the XRD patterns of the SCs were obtained, as shown in Fig. 2a. All the samples exhibited two broad peaks around $23.5^{\circ}$ and $43.2^{\circ}$, corresponding to the (002) and (100) crystal faces of graphite, respectively $[44,45]$. Using Bragg's equation, the interlayer spacing $\left(d_{002}\right)$ of the samples was calculated as $\sim 0.4 \mathrm{~nm}$, which is consistent with the HRTEM results. This large interlayer spacing accelerated the diffusion of $\mathrm{Na}$ ions in the battery system, enhancing the electrochemical utilization. Figure $2 b$ shows the Raman spectra of the SCs. Two bands centered at 1350 and $1590 \mathrm{~cm}^{-1}$ are observed, which
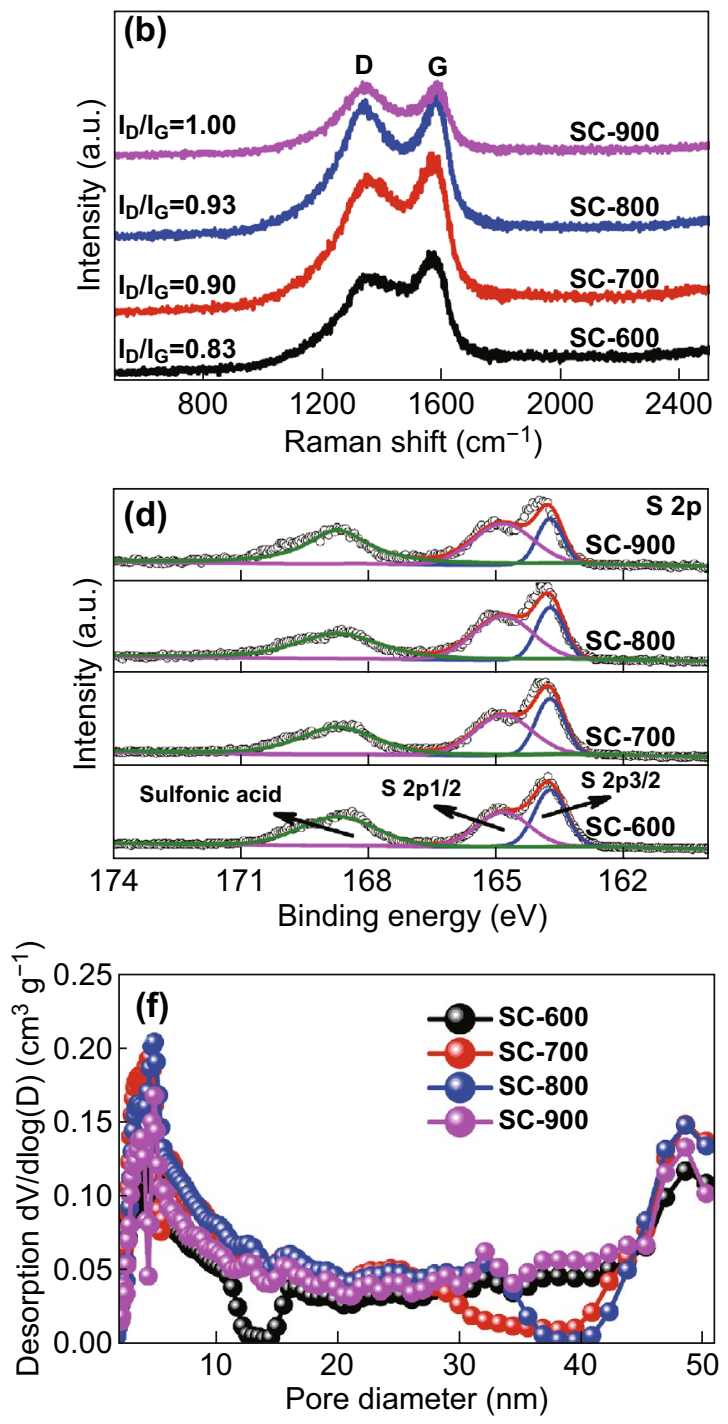

Fig. 2 a XRD patterns and b Raman spectra of SC-600, SC-700, SC-800, and SC-900. c XPS C 1s profile of SC-800. d XPS S 2p profiles. e Nitrogen sorption isotherms and $\mathbf{f}$ pore-size distributions of SC-600, SC-700, SC-800, and SC-900 
are the D-band and G-band of C, respectively [46, 47]. Generally, the D-band represents the disorder carbon, and the G-band is related to the graphitic carbon. Hence, the intensity ratio of the D-band to the G-band $\left(I_{\mathrm{D}} / I_{\mathrm{G}}\right)$ indicates the degree of disorder for carbon materials. $I_{\mathrm{D}} / I_{\mathrm{G}}$ was calculated as $0.83,0.90,0.93$, and 1.00 for SC-600, SC-700, SC-800, and SC-900, respectively. These values indicate that more defects were generated at a higher temperature, providing more active sites for Na-ion accommodation [48].

To investigate the compositions of the SCs, XPS was performed. The S contents in SC-600, SC-700, SC-800, and SC-900 were $9.79,8.69,6.25$, and 4.89 at\%, respectively, indicating a declining trend with an increase in the carbonization temperature. Figure $2 \mathrm{c}$ shows the high-resolution $\mathrm{C} 1 \mathrm{~s}$ spectrum of SC-800, which can be deconvoluted into three peaks. Among them, the spectrum is principally constituted by the $\mathrm{C}-\mathrm{C}$ bond, indicating that the SCMP was carbonized after the pyrolysis. The other two peaks are attributed to the $\mathrm{C}-\mathrm{S}$ and $\mathrm{C}-\mathrm{O}$ bonds, indicating that the $\mathrm{S}$ atoms were linked tightly to the SCs. Figure $2 \mathrm{~d}$ shows the high-resolution S 2p spectra of SC-600, SC-700, SC-800, and SC-900. After fitting, all the spectra could be deconvoluted into three peaks. Among them, the two peaks at 163.7 and $164.8 \mathrm{eV}$ are attributed to $S 2 p_{3 / 2}$ and $S 2 p_{1 / 2}$, respectively, for the $-\mathrm{C}-\mathrm{S}-\mathrm{C}-$ covalent bond of thiophene $\mathrm{S}$. The other peak at $168.4 \mathrm{eV}$ corresponds to the $\mathrm{C}-\mathrm{SO}_{x}-\mathrm{C}(x=2-4)$ group, confirming that $\mathrm{S}$ was successfully incorporated into the carbon skeletons $[9,49,50]$. Notably, $\mathrm{O}$ was also present in the doped samples (as shown in Fig. S6), which should come from the unreacted anhydride $\mathrm{C}$ (as shown in Fig. S2). The doped $\mathrm{O}$ mainly bonded with $\mathrm{S}$, forming a sulfonate group, as confirmed by the $\mathrm{C}-\mathrm{SO}_{x}-\mathrm{C}(x=2-4)$ group observed in Fig. 2d. This group may have increased the interlayer distance of the SCs owing to its relatively large size. The O contents in SC-600, SC-700, SC-800, and SC-900 were 14.2, $11.64,9.19$, and 8.20 at\%, respectively, indicating a declining with the increasing carbonization temperature, similar to that of the $\mathrm{S}$ content.

Figure $2 \mathrm{e}, \mathrm{f}$ shows the $\mathrm{N}_{2}$ sorption isotherms and pore-size distributions of the samples. According to the International Union of Pure and Applied Chemistry (IUPAC) classification, the isotherms of SCs (Fig. 2e) exhibit typical type IV curves with a hysteresis loop located in the relative pressure range of 0.1-0.9, indicating that all SCs have a mesoporous structure. Calculations using the BET model indicated that the specific surface areas of SC-600, SC-700, SC-800, and
SC-900 were 446.1, 388.6, 331.4, and $320.5 \mathrm{~m}^{2} \mathrm{~g}^{-1}$, respectively. The BET specific surface area of the SCs decreased with the increasing pyrolysis temperature. This phenomenon was due to the reduction in the $\mathrm{S}$ doping content with the increasing pyrolysis temperature, which resulted in the decrease in structural defects in the SCs [51]. The pore-size distributions of the PCSs were analyzed via nonlocal density functional theory calculations, as shown in Fig. 2f. As expected, the pores of the SCs were mainly distributed in the mesoporous range, from 2 to $10 \mathrm{~nm}$. Owing to the similar mesoporous structures of the SCs, a larger specific surface area of SCs provided a larger contact interface area between the electrode and the electrolyte [52, 53].

\subsection{Electrochemical Performance}

To evaluate the electrochemical performance, the initial three CV curves of SC-800 were obtained, as shown in Fig. 3a. In the first cycle, a large irreversible cathodic peak was observed at approximately $0.8 \mathrm{~V}$, which was due to the formation of a solid-electrolyte interphase (SEI) layer [9]. Additionally, a redox couple located at $1.1 / 1.8 \mathrm{~V}$ was observed, which is ascribed to the redox reaction of doped $\mathrm{S}$ in SC-800. This phenomenon is similar to those observed in previously reported $\mathrm{Na}-\mathrm{S}$ batteries $[54,55]$. Owing to the electrochemical activity of the covalently bonded S, our SCs could accommodate more Na ions, improving the reversible capacity [56]. Figure 3b displays the galvanostatic charge/ discharge profiles of the SC-800 electrode at a current density of $50 \mathrm{~mA} \mathrm{~g}^{-1}$. Visible plateaus around $1.1 / 1.8 \mathrm{~V}$ are observed, corresponding to the redox reaction. After the initial three cycles, the specific capacity of SC-800 changed little.

Figure 3c shows the EIS spectra of the SCs electrodes, which were obtained after 100 cycles at $50 \mathrm{~mA} \mathrm{~g}^{-1}$. The Nyquist plots of the SCs electrodes were composed of an indistinct semicircle, a large semicircle, and a sloping line in the high-, medium-, and low-frequency regions, respectively. Among them, the indistinct small semicircle was related to the resistance of the SEI layer and the constantphase element (CPE1). The large semicircle is attributed to the charge-transfer resistance $\left(R_{\mathrm{ct}}\right)$ and $\mathrm{CPE}_{2}$. The sloping line corresponds to the Warburg impedance $\left(Z_{\mathrm{w}}\right)$ stemming from the diffusion of $\mathrm{Na}$ ions. (The corresponding equivalent circuit of the EIS spectra is shown in Fig. 3d.) The $R_{\mathrm{ct}}$ 

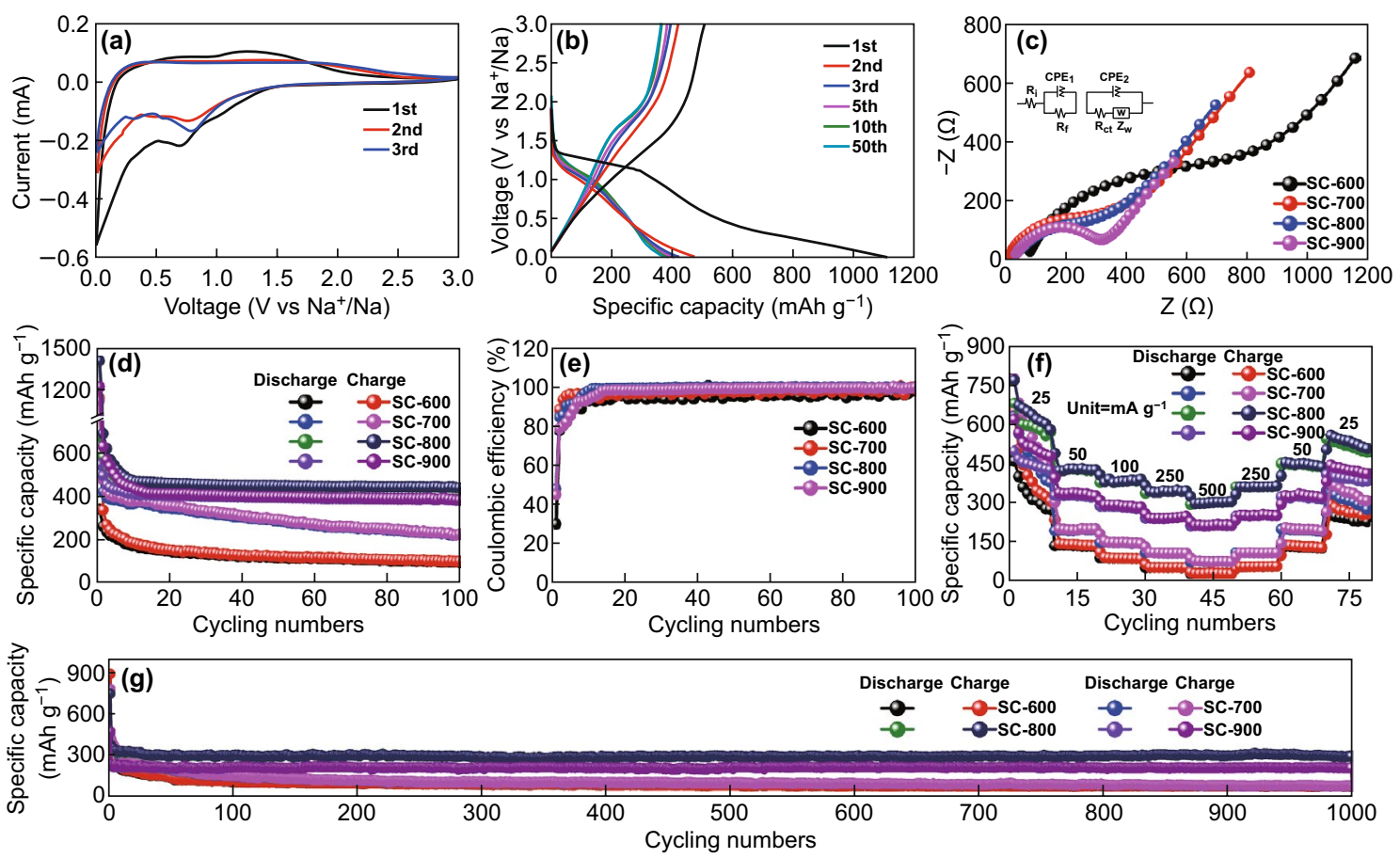

Fig. 3 a CV curves and b charge/discharge profiles of SC-800. $\mathbf{c}$ Electrochemical impedance spectra, d cycling performance, e Coulombic efficiencies, $\mathbf{f}$ rate performance, and $\mathbf{g}$ long-term cycling performance of SC-600, SC-700, SC-800, and SC-900

values were $411.8,255.9,183.1$, and $222.5 \Omega$ for SC-600, SC-700, SC-800, and SC-900, respectively, which were obtained from the fitting results based on the equivalent circuit model shown in Fig. 3c. SC-800 had the lowest $R_{\mathrm{ct}}$, which facilitated the charge transfer and was thus beneficial to the Na-ion storage performance.

Figure 3d, e shows the cycling performance and corresponding Coulombic efficiencies of the SCs. All the SCs exhibited capacity fading in the initial several cycles, which is ascribed to the formation of the SEI layer and reactions between $\mathrm{Na}$ ions and surface functional groups or adsorbed molecules [57]. After the initial several cycles, the Coulombic efficiencies of all the electrodes improved to nearly 99\%, indicating that the SCs electrodes had excellent reversibility for Na-ion storage. Among all the samples, the SC-800 electrode exhibited the highest stable reversible capacity of $440 \mathrm{mAh} \mathrm{g}^{-1}$ at $100 \mathrm{~mA} \mathrm{~g}^{-1}$ after 100 cycles, while the reversible capacities of SC-600, SC-700, and SC-900 electrodes were 97, 224, and $384 \mathrm{mAh} \mathrm{g}^{-1}$, respectively. Although the S content in the SCs decreased with an increase in the temperature (as indicated by XPS), leading to the reduction in the reversible capacity [48], the high $I_{\mathrm{D}} / I_{\mathrm{G}}$ ratio and low $R_{\mathrm{ct}}$ of SC-800 indicated that the disordered structure with rich active sites offered insertion/deinsertion of $\mathrm{Na}$ ions and enhanced the electron-transfer ability [58, 59]. Therefore, SC-800 exhibited a superior Na-ion storage capability.

To further evaluate the electrochemical performance of the SCs, the rate performance was examined, as shown in Fig. 3f. The results indicated that the SC-800 electrode delivered reversible capacities of 570, 426, 389, 344, and $304 \mathrm{mAh} \mathrm{g}^{-1}$ at $25,50,100,250$, and $500 \mathrm{~mA} \mathrm{~g}^{-1}$, respectively. Thus, SC-800 exhibited superior rate performance to the other samples. When the current density recovered to $25 \mathrm{~mA} \mathrm{~g}^{-1}$, the capacity returned to $534 \mathrm{mAh} \mathrm{g}^{-1}$, indicating the excellent recoverability of the electrode. The excellent rate capability and recoverability of SC-800 were mainly attributed to the $\mathrm{S}$ doping, which increased the electrical conductivity and facilitated Na-ion transport by increasing the interlayer spacing [22]. The long-term cycling performance of the SCs was evaluated at a current density of $500 \mathrm{~mA} \mathrm{~g}^{-1}$, as shown in Fig. $4 \mathrm{a}$. The reversible capacity of SC-800 reached $378 \mathrm{mAh} \mathrm{g}^{-1}$ in the first cycle and was stabilized at $297 \mathrm{mAh} \mathrm{g}^{-1}$ after 1000 cycles, which was significantly higher than those of SC-600 (76 $\left.\mathrm{mAh} \mathrm{g}^{-1}\right)$, SC-700 $\left(84 \mathrm{mAh} \mathrm{g}^{-1}\right)$, and SC-900 $\left(212 \mathrm{mAh} \mathrm{g}^{-1}\right)$. To assess the 

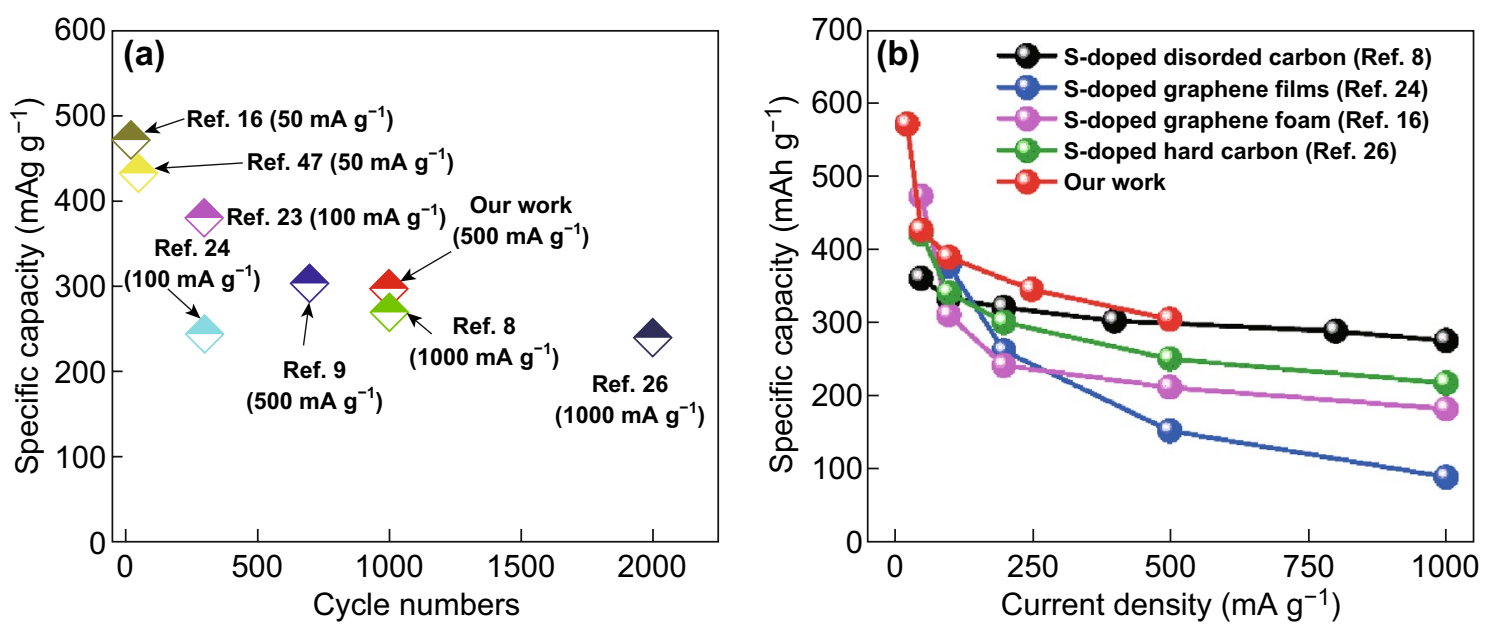

Fig. 4 a Long-term cycling performance and $\mathbf{b}$ rate performance of other S-doped C-based materials for comparison

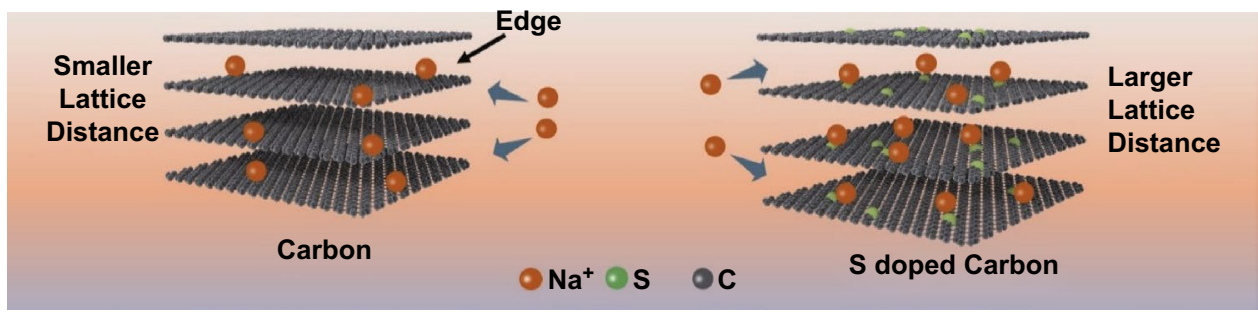

Fig. 5 Possible Na-ion storage mechanism for SCs

Na-ion storage performance of our SCs, previously reported S-doped carbons were examined for comparison, as shown in Fig. 4a, b. Our SCs exhibited excellent rate performance, a high reversible capacity, and a stable cycling life, outperforming the other S-doped carbon materials.

The SCs exhibited better Na-ion storage performance than previously reported carbon materials without $\mathrm{S}$ doping [60, 61]. The reason for this was analyzed as follows. According to calculations performed by $\mathrm{Yu}$ et al. [61], the lattice distance of carbon is increased by $\mathrm{S}$ doping, which is consistent with our TEM results in Fig. 1f. Because of the small lattice distance, the adsorption energy between carbon and $\mathrm{Na}$ ions was $0.365 \mathrm{eV}$, illustrating that the adsorption of $\mathrm{Na}$ ions in the interior of carbon was unstable, and the capacity mainly came from the edge of carbon [61]. After the doping, the lattice distance was increased, and the adsorption energy between the S-doped carbon and $\mathrm{Na}$ ions was enhanced $(-0.216 \mathrm{eV})$, improving the stability of Na-ion adsorption [61]. The corresponding schematic is shown in Fig. 5.
To further illustrate the reaction mechanism of the SCs for Na-ion storage, ex situ XPS profiles of SC-800 in different charge/discharge states for the initial cycle were obtained, as shown in Fig. 6. There was a peak in the $\mathrm{Na} 2 \mathrm{p}$ spectra after discharging (Fig. 6b), indicating that $\mathrm{Na}$ ions were inserted in SC-800. A significant shift was observed after discharging, which is attributed to the different states of Naion insertion [62]. After charging to $3 \mathrm{~V}$, the peak returned to its original position, indicating the reversibility of our $\mathrm{SCs}$ for Na-ion storage [62]. The Na 2p peak still existed after cycling, owing to the formation of the SEI layer. Figure $6 c$ shows the XPS C 1s profiles of SC-800 in different states. Clearly, the intensity of the peak corresponding to the $\mathrm{C}-\mathrm{C}$ bond was reduced after discharging to $0.005 \mathrm{~V}$ and then increased after charging to $3 \mathrm{~V}$, indicating that our SCs had good reversibility for Na-ion storage. Additionally, a peak at $289.6 \mathrm{eV}$ existed after discharging. This peak corresponds to the $\mathrm{O}-\mathrm{C}=\mathrm{O}$ bond and is attributed to the formation of organic matter from the SEI layer $[63,64]$. To further investigate the capacity contribution from $S$, the XPS $S 2 p$ 


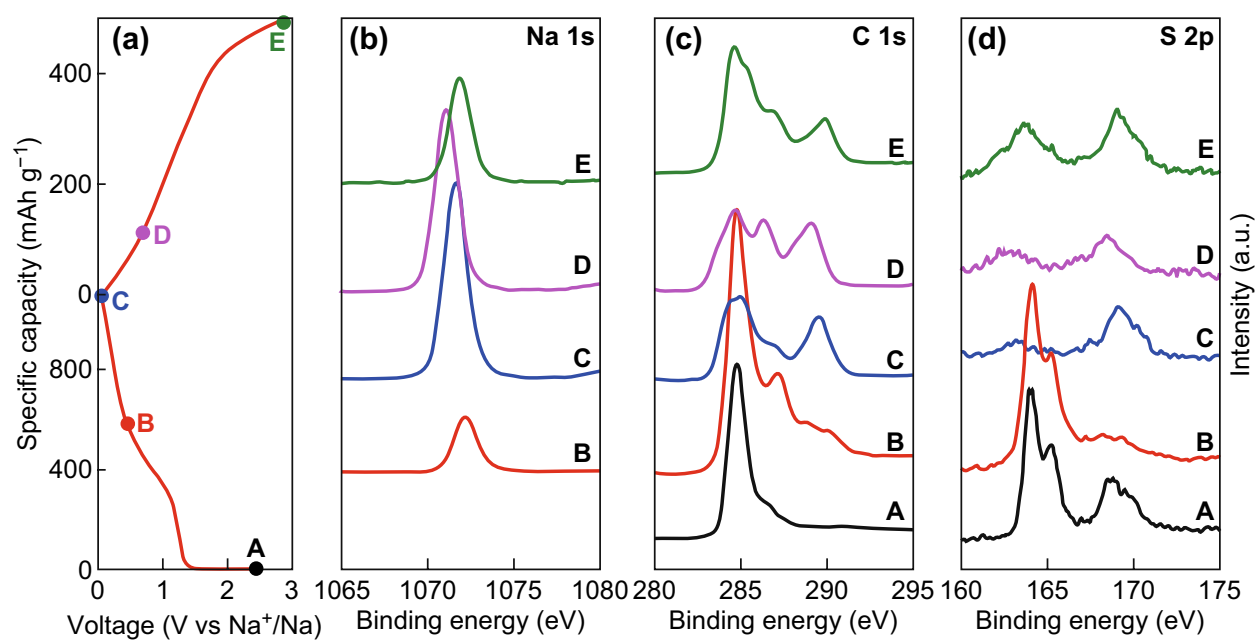

Fig. 6 Ex situ XPS profiles of SC-800 in different states during the initial charge/discharge cycle: a corresponding voltage states; $\mathbf{b}$ Na 1 s, $\mathbf{c}$ C $1 \mathrm{~s}$, and $\mathbf{d} \mathrm{S} 2 \mathrm{p}$ XPS profiles

profiles were obtained, as shown in Fig. 6d. Thiophene S was transformed into oxidized $\mathrm{S}$ after discharging, indicating that the Na ions reacted with the doped S in the SCs, including the reversible part $\left(\mathrm{Na}_{2} \mathrm{~S}\right)$ and irreversible part $\left(\mathrm{Na}_{2} \mathrm{SO}_{4}\right)$. For the reversible part, $\mathrm{Na}$ ions reacted with $\mathrm{C}-\mathrm{S}$ bonds, forming C-S-Na bonds. For the irreversible part, the reaction was mainly caused by the formation of the SEI layer. To further analyze the SEI layer, the $\mathrm{Cl} 2 \mathrm{p}$ XPS profile after the initial cycle was obtained, as shown in Fig. S7. Two peaks at 199.1 and $200.8 \mathrm{eV}$ were observed, which were due to the $\mathrm{Na}-\mathrm{Cl}$ bond, indicating the presence of $\mathrm{NaCl}$ in the SEI layer [65].

To analyze the possible storage mechanism of the SCs electrodes for NIBs, the electrochemical kinetics for Naion storage were investigated. Figure $7 \mathrm{a}$ shows the $\mathrm{CV}$ profiles of SC-800 at different sweep rates ranging from 0.2 to $2 \mathrm{mV} \mathrm{s}^{-1}$. With increasing sweep rate, all the $\mathrm{CV}$ curves exhibited similar shapes, and slight shifts of the cathodic and anodic peaks were observed owing to the contribution of the capacitive characteristic. To analyze this characteristic, the relationship between the current and sweep rate was calculated according to the literatures (Eqs. 1 and 2) [66, 67]:

$i=a v^{b}$

$\log i=b \log v+\log a$

where $i$ and $v$ represent the current density and sweep rate, respectively, and $a$ and $b$ are constants. According to the literature, the diffusion-controlled process is dominant if $b$ is close to 0.5 . Otherwise, the predominant mechanism is the surface-limited capacitive characteristic ( $b$ close to 1 ). Using Eq. 2, we calculated the $b$ values from the slope of the graph of $\log i$ versus $\log v$. The $b$ values of peaks 1 and 2 were 0.77 and 0.93, respectively, as shown in Fig. 7b. These results indicate that the capacity of the SC-800 electrode was dominated by the capacitive contribution. To confirm the total contribution for the SC-800 electrode, the fractions of capacitor-like $\left(k_{1} v\right)$ and diffusion-controlled $\left(k_{2} v^{1 / 2}\right)$ currents were distinguished at a fixed potential $(V)$ according to Eq. 3 [68-70]:

$i(V)=k_{1} v+k_{2} v^{1 / 2}$,

where $k_{1}$ and $k_{2}$ are constants. Equation 3 can be rewritten as Eq. 4:

$i(V) / v^{1 / 2}=k_{1} v^{1 / 2}+k_{2}$.

The values of $k_{1}$ and $k_{2}$ are easily calculated via plotting the fitting lines of $i(V) / v^{1 / 2}$ and $v^{1 / 2}$, and then the capacitive current $i_{c}(V)=k_{1} v$ can be distinguished from the total measured current. For example, the capacitive current was compared with the tested current from the CV curves, as shown in Fig. 7c. The results indicated that the capacitive contribution to the capacity was $69 \%$ at a sweep rate of $1.0 \mathrm{mV} \mathrm{s}^{-1}$. Figure $7 \mathrm{~d}$ shows the capacitive contribution of SC-800 at sweep rates of $0.4,0.6,0.8$, and $1.0 \mathrm{mV} \mathrm{s}^{-1}$. The corresponding capacitive contribution ratios were $58 \%, 62 \%$, $66 \%$, and $69 \%$. The capacitive contribution exhibited a rising trend with the increasing scan rate. The high capacitive contribution is ascribed to the short ion-diffusion length and rapid electron transfer and was responsible for the high-rate 

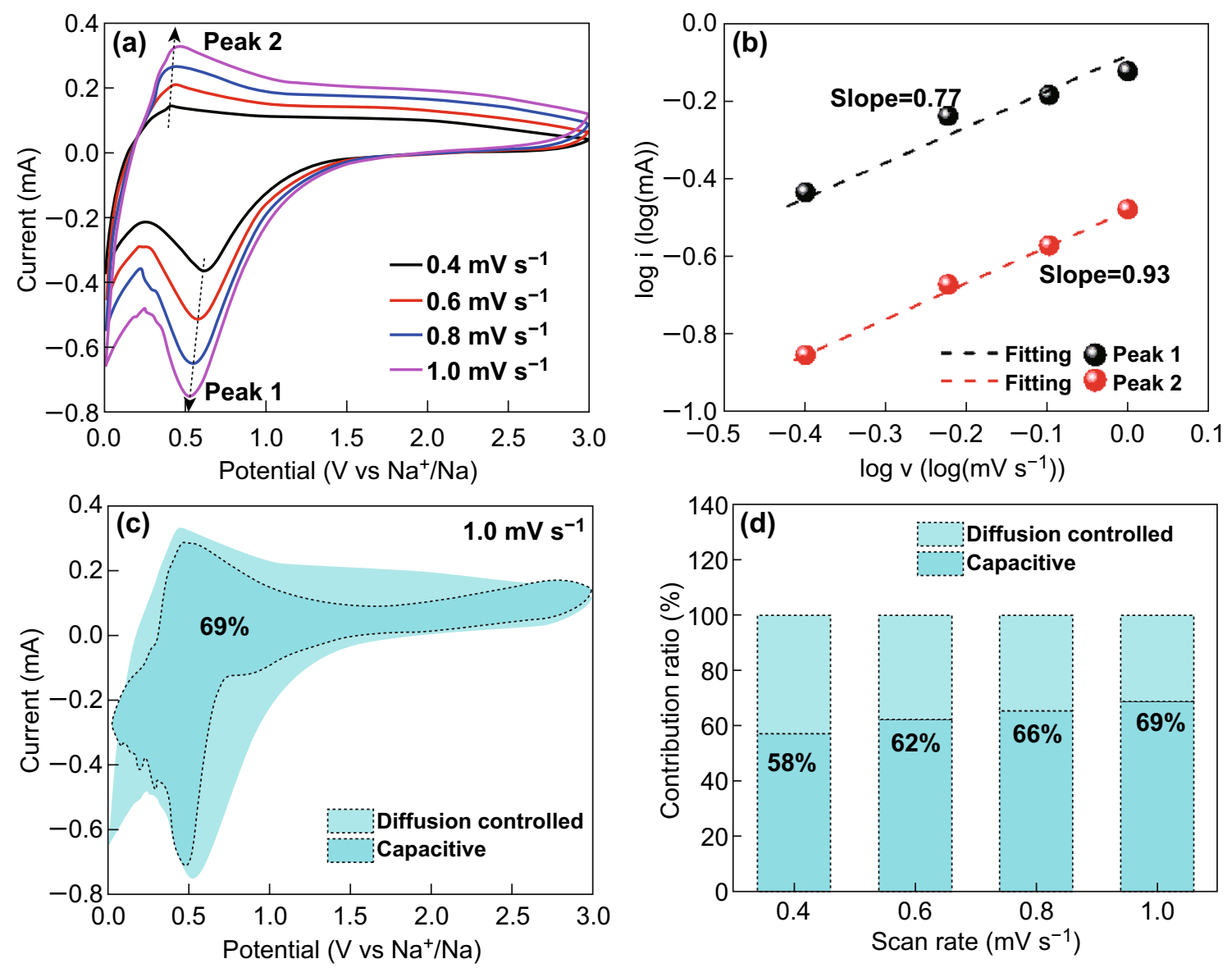

Fig. 7 a CV curves of SC-800 at different sweep rates after cycling. b Relationship between $\log (i)$ and $\log (v)$ for SC-800. c Voltammetric response $\left(1.0 \mathrm{mV} \mathrm{s}^{-1}\right)$ for $\mathrm{SC}-800$ and $\mathbf{d}$ contributions of the capacitive and diffusion-controlled charges at different sweep rates

capability [70]. Because of the capacitive behavior, a large number of $\mathrm{Na}$ ions could be easily stored on the surface or near-surface sites of the electrode, resulting in excellent cycling stability [68].

\section{Conclusions}

We successfully synthesized SCs from CMPs via a convenient, economical, and scalable method. Owing to the structural features provided by the CMP precursor, such as the large interlayer spacing, enhanced charge-transfer ability, and hierarchical pore distribution, SC-800 exhibited a high reversible capacity $\left(440 \mathrm{mAh} \mathrm{g}^{-1}\right.$ at $\left.50 \mathrm{~mA} \mathrm{~g}^{-1}\right)$, excellent rate performance, and superior cycling performance $\left(297 \mathrm{mAh} \mathrm{g}^{-1}\right.$ at a current density of $500 \mathrm{~mA} \mathrm{~g}^{-1}$ after 1000 cycles) for NIBs. The excellent performance of the SCs is attributed to the expanded lattice distance after S doping. Furthermore, we employed ex situ XPS to investigate the electrochemical reaction mechanism of the SCs during sodiation-desodiation, which can highlight the role of doped $\mathrm{S}$ for Na-ion storage.

Acknowledgements Financial support from National Natural Science Foundation of China (Nos. 51702056 and 51772135), the Ministry of Education of China (6141A02022516), and China Postdoctoral Science Foundation (2017M622902 and 2019T120790) is gratefully acknowledged.

Open Access This article is distributed under the terms of the Creative Commons Attribution 4.0 International License (http:// creativecommons.org/licenses/by/4.0/), which permits unrestricted use, distribution, and reproduction in any medium, provided you give appropriate credit to the original author(s) and the source, provide a link to the Creative Commons license, and indicate if changes were made. 
Electronic supplementary material The online version of this article (https://doi.org/10.1007/s40820-019-0291-z) contains supplementary material, which is available to authorized users.

\section{References}

1. H. Yang, H.-H. Wu, M. Ge, L. Li, Y. Yuan et al., Simultaneously dual modification of Ni-rich layered oxide cathode for high-energy lithium-ion batteries. Adv. Funct. Mater. 29, 1808825 (2019). https://doi.org/10.1002/adfm.201808825

2. J.-L. Shi, D.-D. Xiao, M. Ge, X. Yu, Y. Chu et al., Highcapacity cathode material with high voltage for Li-ion batteries. Adv. Mater. 30, 1705575 (2018). https://doi.org/10.1002/ adma.201705575

3. J. Li, L. Han, X. Zhang, G. Zhu, T. Chen, T. Lu, L. Pan, $\mathrm{Sb}_{2} \mathrm{O}_{5} /$ Co-containing carbon polyhedra as anode material for highperformance lithium-ion batteries. Chem. Eng. J. 370, 800809 (2019). https://doi.org/10.1016/j.cej.2019.03.244

4. L. Wan, D. Yan, X. Xu, J. Li, T. Lu, Y. Gao, Y. Yao, L. Pan, Self-assembled 3D flower-like $\mathrm{Fe}_{3} \mathrm{O}_{4} / \mathrm{C}$ architecture with superior lithium ion storage performance. J. Mater. Chem. A 6, 24940-24948 (2018). https://doi.org/10.1039/C8TA06482B

5. M.S. Islam, C.A. Fisher, Lithium and sodium battery cathode materials: computational insights into voltage, diffusion and nanostructural properties. Chem. Soc. Rev. 43, 185-204 (2014). https://doi.org/10.1039/C3CS60199D

6. B.L. Ellis, L.F. Nazar, Sodium and sodium-ion energy storage batteries. Curr. Opin. Solid State Mater. Sci. 16, 168-177 (2012). https://doi.org/10.1016/j.cossms.2012.04.002

7. L. Zheng, L. Li, R. Shunmugasundaram, M.N. Obrovac, Effect of controlled-atmosphere storage and ethanol rinsing on $\mathrm{NaNi}_{0.5} \mathrm{Mn}_{0.5} \mathrm{O}_{2}$ for sodium-ion batteries. ACS Appl. Mater. Interfaces 10, 38246-38254 (2018). https://doi.org/10.1021/ acsami.8b14209

8. J. Li, X. Zhang, L. Han, D. Yan, S. Hou, T. Lu, Y. Yao, L. $\mathrm{Pan}, \mathrm{TiO}_{2}$ nanocrystals embedded in sulfur-doped porous carbon as high-performance and long-lasting anode materials for sodium-ion batteries. J. Mater. Chem. A 6, 24224-24231 (2018). https://doi.org/10.1039/C8TA05617J

9. W. Li, M. Zhou, H. Li, K. Wang, S. Cheng, K. Jiang, A high performance sulfur-doped disordered carbon anode for sodium ion batteries. Energy Environ. Sci. 8, 2916-2921 (2015). https ://doi.org/10.1039/C5EE01985K

10. L. Qie, W. Chen, X. Xiong, C. Hu, F. Zou, P. Hu, Y. Huang, Sulfur-doped carbon with enlarged interlayer distance as a high-performance anode material for sodium-ion batteries. Adv. Sci. 2, 1500195 (2015). https://doi.org/10.1002/ advs.201500195

11. S.Y. Hong, Y. Kim, Y. Park, A. Choi, N.-S. Choi, K.T. Lee, Charge carriers in rechargeable batteries: $\mathrm{Na}$ ions vs $\mathrm{Li}$ ions. Energy Environ. Sci. 6, 2067-2081 (2013). https://doi. org/10.1039/c3ee40811f

12. Y. Bao, Y. Huang, X. Song, J. Long, S. Wang, L.-X. Ding, H. Wang, Heteroatom doping and activation of carbon nanofibers enabling ultrafast and stable sodium storage. Electrochim.
Acta 276, 304-310 (2018). https://doi.org/10.1016/j.elect acta.2018.04.207

13. C. Chen, M. Wu, Z. Xu, T. Feng, J. Yang, Z. Chen, S. Wang, Y. Wang, Tailored N-doped porous carbon nanocomposites through MOF self-assembling for $\mathrm{Li} / \mathrm{Na}$ ion batteries. J. Colloid Interface Sci. 538, 267-276 (2019). https://doi. org/10.1016/j.jcis.2018.11.101

14. Q. Li, Y. Zhu, P. Zhao, C. Yuan, M. Chen, C. Wang, Commercial activated carbon as a novel precursor of the amorphous carbon for high-performance sodium-ion batteries anode. Carbon 129, 85-94 (2018). https://doi.org/10.1016/j.carbo n.2017.12.008

15. X.-F. Luo, C.-H. Yang, Y.-Y. Peng, N.-W. Pu, M.-D. Ger, C.-T. Hsieh, J.-K. Chang, Graphene nanosheets, carbon nanotubes, graphite, and activated carbon as anode materials for sodiumion batteries. J. Mater. Chem. A 3, 10320-10326 (2015). https ://doi.org/10.1039/C5TA00727E

16. M.M. Islam, C.M. Subramaniyam, T. Akhter, S.N. Faisal, A.I. Minett, H.K. Liu, K. Konstantinov, S.X. Dou, Three dimensional cellular architecture of sulfur doped graphene: selfstanding electrode for flexible supercapacitors, lithium ion and sodium ion batteries. J. Mater. Chem. A 5, 5290-5302 (2017). https://doi.org/10.1039/C6TA10933K

17. D. Li, H. Chen, G. Liu, M. Wei, L.-X. Ding, S. Wang, H. Wang, Porous nitrogen doped carbon sphere as high performance anode of sodium-ion battery. Carbon 94, 888-894 (2015). https://doi.org/10.1016/j.carbon.2015.07.067

18. K.-L. Hong, L. Qie, R. Zeng, Z.-Q. Yi, W. Zhang et al., Biomass derived hard carbon used as a high performance anode material for sodium ion batteries. J. Mater. Chem. A 2, 12733 12738 (2014). https://doi.org/10.1039/C4TA02068E

19. B. Quan, S.-H. Yu, D.Y. Chung, A. Jin, J.H. Park, Y.-E. Sung, Y. Piao, Single source precursor-based solvothermal synthesis of heteroatom-doped graphene and its energy storage and conversion applications. Sci. Rep. 4, 5639 (2014). https://doi. org/10.1038/srep05639

20. Y. Zhou, Y. Leng, W. Zhou, J. Huang, M. Zhao, Sulfur and nitrogen self-doped carbon nanosheets derived from peanut root nodules as high-efficiency non-metal electrocatalyst for hydrogen evolution reaction. Nano Energy 16, 357-366 (2015). https://doi.org/10.1016/j.nanoen.2015.07.008

21. Y. Li, Z. Wang, L. Li, S. Peng, L. Zhang, M. Srinivasan, S. Ramakrishna, Preparation of nitrogen-and phosphorous codoped carbon microspheres and their superior performance as anode in sodium-ion batteries. Carbon 99, 556-563 (2016). https://doi.org/10.1016/j.carbon.2015.12.066

22. B. Quan, A. Jin, S.H. Yu, S.M. Kang, J. Jeong, H.D. Abruña, L. Jin, Y. Piao, Y.E. Sung, Solvothermal-derived s-doped graphene as an anode material for sodium-ion batteries. Adv. Sci. 5, 1700880 (2018). https://doi.org/10.1002/advs.201700880

23. X. Deng, K. Xie, L. Li, W. Zhou, J. Sunarso, Z. Shao, Scalable synthesis of self-standing sulfur-doped flexible graphene films as recyclable anode materials for low-cost sodium-ion batteries. Carbon 107, 67-73 (2016). https://doi.org/10.1016/j.carbo n.2016.05.052 
24. J. Yang, X. Zhou, D. Wu, X. Zhao, Z. Zhou, S-doped N-rich carbon nanosheets with expanded interlayer distance as anode materials for sodium-ion batteries. Adv. Mater. 29, 1604108 (2017). https://doi.org/10.1002/adma.201604108

25. Z. Hong, Y. Zhen, Y. Ruan, M. Kang, K. Zhou, J.M. Zhang, Z. Huang, M. Wei, Rational design and general synthesis of S-doped hard carbon with tunable doping sites toward excellent Na-ion storage performance. Adv. Mater. 30, 1802035 (2018). https://doi.org/10.1002/adma.201802035

26. M. Lu, W. Yu, J. Shi, W. Liu, S. Chen, X. Wang, H. Wang, Self-doped carbon architectures with heteroatoms containing nitrogen, oxygen and sulfur as high-performance anodes for lithium-and sodium-ion batteries. Electrochim. Acta 251, 396-406 (2017). https://doi.org/10.1016/j.elect acta.2017.08.131

27. Z. Xiang, Y. Xue, D. Cao, L. Huang, J.F. Chen, L. Dai, Highly efficient electrocatalysts for oxygen reduction based on $2 \mathrm{D}$ covalent organic polymers complexed with non-precious metals. Angew. Chem. Int. Ed. 53, 2433-2437 (2014). https://doi. org/10.1002/anie.201308896

28. J. Zhu, C. Yang, C. Lu, F. Zhang, Z. Yuan, X. Zhuang, Twodimensional porous polymers: from sandwich-like structure to layered skeleton. Acc. Chem. Res. 51, 3191-3202 (2018). https://doi.org/10.1021/acs.accounts.8b00444

29. K. Yuan, X. Zhuang, H. Fu, G. Brunklaus, M. Forster, Y. Chen, X. Feng, U. Scherf, Two-dimensional core-shelled porous hybrids as highly efficient catalysts for the oxygen reduction reaction. Angew. Chem. Int. Ed. 55, 6858-6863 (2016). https://doi.org/10.1002/anie.201600850

30. K. Yuan, P. Guo-Wang, T. Hu, L. Shi, R. Zeng, M. Forster, T. Pichler, Y. Chen, U. Scherf, Nanofibrous and graphene-templated conjugated microporous polymer materials for flexible chemosensors and supercapacitors. Chem. Mater. 27, 74037411 (2015). https://doi.org/10.1021/acs.chemmater.5b03290

31. J.-X. Jiang, F. Su, H. Niu, C.D. Wood, N.L. Campbell, Y.Z. Khimyak, A.I. Cooper, Conjugated microporous poly (phenylene butadiynylene)s. Chem. Commun. (2008). https://doi. org/10.1039/B715563H

32. L. Chen, Y. Yang, D. Jiang, CMPs as scaffolds for constructing porous catalytic frameworks: a built-in heterogeneous catalyst with high activity and selectivity based on nanoporous metalloporphyrin polymers. J. Am. Chem. Soc. 132, 9138-9143 (2010). https://doi.org/10.1021/ja1028556

33. J.-X. Jiang, A. Trewin, D.J. Adams, A.I. Cooper, Band gap engineering in fluorescent conjugated microporous polymers. Chem. Sci. 2, 1777-1781 (2011). https://doi.org/10.1039/ c1sc00329a

34. X. Feng, Y. Liang, L. Zhi, A. Thomas, D. Wu, I. Lieberwirth, U. Kolb, K. Müllen, Synthesis of microporous carbon nanofibers and nanotubes from conjugated polymer network and evaluation in electrochemical capacitor. Adv. Funct. Mater. 19, 2125-2129 (2009). https://doi.org/10.1002/adfm.200900264

35. Y. Xu, S. Jin, H. Xu, A. Nagai, D. Jiang, Conjugated microporous polymers: design, synthesis and application. Chem. Soc. Rev. 42, 8012-8031 (2013). https://doi.org/10.1039/c3cs6 $0160 \mathrm{a}$
36. A.I. Cooper, Conjugated microporous polymers. Adv. Mater. 21, 1291-1295 (2009). https://doi.org/10.1002/adma.20080 1971

37. R. Dawson, A.I. Cooper, D.J. Adams, Nanoporous organic polymer networks. Prog. Polym. Sci. 37, 530-563 (2012). https://doi.org/10.1016/j.progpolymsci.2011.09.002

38. J.X. Jiang, F. Su, A. Trewin, C.D. Wood, N.L. Campbell et al., Conjugated microporous poly (aryleneethynylene) networks. Angew. Chem. Int. Ed. 46, 8574-8578 (2007). https://doi.org/10.1002/anie.200701595

39. K. Yuan, T. Hu, Y. Xu, R. Graf, L. Shi, M. Forster, T. Pichler, T. Riedl, Y. Chen, U. Scherf, Nitrogen-doped porous carbon/graphene nanosheets derived from two-dimensional conjugated microporous polymer sandwiches with promising capacitive performance. Mater. Chem. Front. 1, 278-285 (2017). https://doi.org/10.1039/C6QM00012F

40. X. Zhuang, D. Gehrig, N. Forler, H. Liang, M. Wagner, M.R. Hansen, F. Laquai, F. Zhang, X. Feng, Conjugated microporous polymers with dimensionality-controlled heterostructures for green energy devices. Adv. Mater. 27, 3789-3796 (2015). https://doi.org/10.1002/adma.201501786

41. L. Hao, J. Ning, B. Luo, B. Wang, Y. Zhang, Z. Tang, J. Yang, A. Thomas, L. Zhi, Structural evolution of 2D microporous covalent triazine-based framework toward the study of high-performance supercapacitors. J. Am. Chem. Soc. 137, 219-225 (2014). https://doi.org/10.1021/ja508 $693 y$

42. Y. Su, Z. Yao, F. Zhang, H. Wang, Z. Mics, E. Cánovas, M. Bonn, X. Zhuang, X. Feng, Sulfur-enriched conjugated polymer nanosheet derived sulfur and nitrogen co-doped porous carbon nanosheets as electrocatalysts for oxygen reduction reaction and zinc-air battery. Adv. Funct. Mater. 26, 58935902 (2016). https://doi.org/10.1002/adfm.201602158

43. J. Wang, L. Yan, Q. Ren, L. Fan, F. Zhang, Z. Shi, Facile hydrothermal treatment route of reed straw-derived hard carbon for high performance sodium ion battery. Electrochim. Acta 291, 188-196 (2018). https://doi.org/10.1016/j.elect acta.2018.08.136

44. L. Xiao, Y. Cao, W.A. Henderson, M.L. Sushko, Y. Shao, J. Xiao, W. Wang, M.H. Engelhard, Z. Nie, J. Liu, Hard carbon nanoparticles as high-capacity, high-stability anodic materials for Na-ion batteries. Nano Energy 19, 279-288 (2016). https://doi.org/10.1016/j.nanoen.2015.10.034

45. G. Xu, J. Han, B. Ding, P. Nie, J. Pan, H. Dou, H. Li, X. Zhang, Biomass-derived porous carbon materials with sulfur and nitrogen dual-doping for energy storage. Green Chem. 17, 1668-1674 (2015). https://doi.org/10.1039/C4GC02185A

46. Y. Li, S. Xu, X. Wu, J. Yu, Y. Wang, Y.-S. Hu, H. Li, L. Chen, X. Huang, Amorphous monodispersed hard carbon micro-spherules derived from biomass as a high performance negative electrode material for sodium-ion batteries. J. Mater. Chem. A 3, 71-77 (2015). https://doi.org/10.1039/ C4TA05451B

47. L. Zeng, W. Li, J. Cheng, J. Wang, X. Liu, Y. Yu, N-doped porous hollow carbon nanofibers fabricated using electrospun polymer templates and their sodium storage properties. 
RSC Adv. 4, 16920-16927 (2014). https://doi.org/10.1039/ C4RA01200C

48. H. Tang, D. Yan, T. Lu, L. Pan, Sulfur-doped carbon spheres with hierarchical micro/mesopores as anode materials for sodium-ion batteries. Electrochim. Acta 241, 63-72 (2017). https://doi.org/10.1016/j.electacta.2017.04.112

49. Y. Yan, Y.-X. Yin, S. Xin, Y.-G. Guo, L.-J. Wan, Ionothermal synthesis of sulfur-doped porous carbons hybridized with graphene as superior anode materials for lithium-ion batteries. Chem. Commun. 48, 10663-10665 (2012). https://doi. org/10.1039/c2cc36234a

50. X. Ma, G. Ning, Y. Kan, Y. Ma, C. Qi, B. Chen, Y. Li, X. Lan, J. Gao, Synthesis of S-doped mesoporous carbon fibres with ultrahigh $\mathrm{S}$ concentration and their application as high performance electrodes in supercapacitors. Electrochim. Acta 150, 108-113 (2014). https://doi.org/10.1016/j.elect acta.2014.10.128

51. M. Chen, S. Jiang, C. Huang, X. Wang, S. Cai, K. Xiang, Y. Zhang, J. Xue, Honeycomb-like nitrogen and sulfur dualdoped hierarchical porous biomass-derived carbon for lithium-sulfur batteries. Chemsuschem 10, 1803-1812 (2017). https://doi.org/10.1002/cssc.201700050

52. B. Wang, X. Zhang, X. Liu, G. Wang, H. Wang, J. Bai, Rational design of $\mathrm{Fe}_{3} \mathrm{O}_{4}$ @ $\mathrm{C}$ yolk-shell nanorods constituting a stable anode for high-performance $\mathrm{Li} / \mathrm{Na}$-ion batteries. J. Colloid Interface Sci. 528, 225-236 (2018). https://doi. org/10.1016/j.jcis.2018.05.086

53. J. Feng, L. Dong, X. Li, D. Li, P. Lu, F. Hou, J. Liang, S.X. Dou, Hierarchically stacked reduced graphene oxide/carbon nanotubes for as high performance anode for sodium-ion batteries. Electrochim. Acta 302, 65-70 (2019). https://doi. org/10.1016/j.electacta.2019.02.008

54. T.H. Hwang, D.S. Jung, J.-S. Kim, B.G. Kim, J.W. Choi, One-dimensional carbon-sulfur composite fibers for $\mathrm{Na}-\mathrm{S}$ rechargeable batteries operating at room temperature. Nano Lett. 13, 4532-4538 (2013). https://doi.org/10.1021/n1402 $513 \mathrm{x}$

55. S. Xin, Y.X. Yin, Y.G. Guo, L.J. Wan, A high-energy roomtemperature sodium-sulfur battery. Adv. Mater. 26, 1261-1265 (2014). https://doi.org/10.1002/adma.201304126

56. Y.S. Yun, V.-D. Le, H. Kim, S.-J. Chang, S.J. Baek et al., Effects of sulfur doping on graphene-based nanosheets for use as anode materials in lithium-ion batteries. J. Power Sources 262, 79-85 (2014). https://doi.org/10.1016/j.jpows our.2014.03.084

57. S.R. Prabakar, J. Jeong, M. Pyo, Nanoporous hard carbon anodes for improved electrochemical performance in sodium ion batteries. Electrochim. Acta 161, 23-31 (2015). https:// doi.org/10.1016/j.electacta.2015.02.086

58. H. Zhang, M. Hu, Q. Lv, L. Yang, R. Lv, Monodisperse nitrogen-doped carbon spheres with superior rate capacities for lithium/sodium ion storage. Electrochim. Acta 297, 365-371 (2019). https://doi.org/10.1016/j.electacta.2018.11.207

59. X. Zhang, D. Li, G. Zhu, T. Lu, L. Pan, Porous $\mathrm{CoFe}_{2} \mathrm{O}_{4}$ nanocubes derived from metal-organic frameworks as highperformance anode for sodium ion batteries. J. Colloid
Interface Sci. 499, 145-150 (2017). https://doi.org/10.1016/j. jcis.2017.03.104

60. V.G. Pol, E. Lee, D. Zhou, F. Dogan, J.M. Calderon-Moreno, C.S. Johnson, Spherical carbon as a new high-rate anode for sodium-ion batteries. Electrochim. Acta 127, 61-67 (2014). https://doi.org/10.1016/j.electacta.2014.01.132

61. D. Xu, C. Chen, J. Xie, B. Zhang, L. Miao, J. Cai, Y. Huang, L. Zhang, A Hierarchical N/S-codoped carbon anode fabricated facilely from cellulose/polyaniline microspheres for high-performance sodium-ion batteries. Adv. Energy Mater. 6, 1501929 (2016). https://doi.org/10.1002/aenm.201501929

62. Y. Li, Y.-S. Hu, X. Qi, X. Rong, H. Li, X. Huang, L. Chen, Advanced sodium-ion batteries using superior low cost pyrolyzed anthracite anode: towards practical applications. Energy Storage Mater. 5, 191-197 (2016). https://doi.org/10.1016/j. ensm.2016.07.006

63. F. Chen, J. Yang, T. Bai, B. Long, X. Zhou, Biomass wastederived honeycomb-like nitrogen and oxygen dual-doped porous carbon for high performance lithium-sulfur batteries. Electrochim. Acta 192, 99-109 (2016). https://doi. org/10.1016/j.electacta.2016.01.192

64. J. Li, W. Qin, J. Xie, H. Lei, Y. Zhu et al., Sulphur-doped reduced graphene oxide sponges as high-performance freestanding anodes for K-ion storage. Nano Energy 53, 415-424 (2018). https://doi.org/10.1016/j.nanoen.2018.08.075

65. H. Chen, X. Chen, Z. Qiao, H. Liu, Release and transformation behavior of $\mathrm{Cl}$ during pyrolysis of torrefied rice straw. Fuel 183, 145-154 (2016). https://doi.org/10.1016/j. fuel.2016.06.031

66. D. Chao, P. Liang, Z. Chen, L. Bai, H. Shen, X.E.A. Liu, Pseudocapacitive Na-ion storage boosts high rate and areal capacity of self-branched 2D layered metal chalcogenide nanoarrays. ACS Nano 10, 10211-10219 (2016). https://doi.org/10.1021/ acsnano.6b05566

67. J. Zhang, W. Zhang, T. He, I.S. Amiinu, Z. Kou, J.E.A. Li, Smart reconstruction of dual-carbon decorated $\mathrm{MnO}$ for anode with high-capacity and ultralong-life lithium storage properties. Carbon 115, 95-104 (2017). https://doi.org/10.1016/j. carbon.2016.12.090

68. W. Tian, H. Hu, Y. Wang, P. Li, J. Liu et al., Metal-organic frameworks mediated synthesis of one-dimensional molybdenum-based/carbon composites for enhanced lithium storage. ACS Nano 12, 1990-2000 (2018). https://doi.org/10.1021/ acsnano.7b09175

69. D. Li, L. Zhang, H. Chen, J. Wang, L.X. Ding, S. Wang, P.J. Ashman, H. Wang, Graphene-based nitrogen-doped carbon sandwich nanosheets: new capacitive process controlled anode material for high-performance sodium-ion batteries. J. Mater. Chem. A 4, 8630-8635 (2016). https://doi.org/10.1039/C6TA0 2139E

70. C. Zhao, C. Yu, M. Zhang, H. Huang, S. Li, X. Han, Z. Liu, J. Yang, W. Xiao, J. Liang, Ultrafine $\mathrm{MoO}_{2}$-carbon microstructures enable ultralong-life power-type sodium ion storage by enhanced pseudocapacitance. Adv. Energy Mater. 7, 1602880 (2017). https://doi.org/10.1002/aenm.201602880 